\title{
A construção discursiva do corpo feminino na representação literária de donzela-guerreira
}

\author{
Milena Santos de JESUS ${ }^{1}$ \\ Sandra Maria Pereira do SACRAMENTO ${ }^{2}$
}

\begin{abstract}
Resumo: O presente artigo tem como objetivo analisar a construção discursiva do corpo feminino na representação literária de donzela-guerreira, e como esse corrobora para a desnaturalização do sexo e para a ruptura dos padrões de gênero. Dessa maneira, observamos a presença da donzela na tradição ocidental, passando pela literatura brasileira até sua aparição nos romances Luzia-Homem (1903), de Domingos Olímpio; Dona Guidinha do Poço (1965), de Manuel Paiva, Grande Sertão: Veredas (1956), de Guimarães Rosa e Memorial de Maria Moura, de 1992, de Raquel de Queiroz. A donzela-guerreira integra a literatura, as civilizações, as culturas, a história e a mitologia. Desse modo, a representação dessa mulher marca o imaginário de diversificadas culturas e possibilita repensamos os papéis da mulher em distintos momentos históricos. Buscamos compreender o corpo da donzela como elemento performativo para a construção de uma identidade feminina que dialoga com o masculino, assimilando seu discurso hegemônico para burlá-lo. A compreensão de performatividade aqui adotada é trazida por Butler (2008). Assim, as contribuições da autora são pertinentes, já que considera que o masculino e feminino não são categorias possuídas de antemão, mas efeitos que produzimos por meio da realização de ações específicas.
\end{abstract}

Palavras-Chave: Literatura. Gênero. Corpo. Discurso.

\section{THE DISCURSIVE CONSTRUCTION OF THE FEMALE BODY IN THE LITERARY REPRESENTATION OF WARRIOR-MAIDEN}

\begin{abstract}
This article aims to analyze the discursive construction of the female body in the literary representation of warrior-maiden, and how this confirms the denaturalization of sex and the disruption of gender patterns. Thus, we observe the presence of the maiden in the Western tradition, from the Brazilian literature until his appearance in the novels Luzia-Homem (1903), by Domingos Olímpio; Dona Guidinha do Poço (1965), by Manuel Paiva, Grande Sertão: Veredas (1956), by Guimarães Rosa and Memorial de Maria Moura (1992), by Raquel de Queiroz. The maiden-warrior integrates literature, civilizations, cultures, history and mythology. Thus, the representation of women marks the imagery of diverse cultures and enables us to rethink the roles of women in different historical moments. We seek to understand the Maiden's body as a performative element for the construction of female identity that speaks to the male, assimilating its hegemonic discourse to circumvent it. The understanding of performativity adopted here is brought by Butler (2008). Thus, the contributions of Butler (2008) are relevant, since it considers that the male and female categories are not held beforehand, but produce effects by performing specific actions.
\end{abstract}

Keywords: Literature. Genre. Body. Speech.

\footnotetext{
${ }^{1}$ Discente do programa de mestrado Linguagens e Representações Universidade Estadual de Santa C(uza) Bolsista do Conselho Nacional de Desenvolvimento Cientifico e Tecnológico (CNPq). e-matl. jsmyllena@yahoo.com.br

${ }^{2}$ Professora titular em Teoria da Literatura (UESC/DLA). Doutora em Letras Vernáculas - Literatura Brasiteira pela UFRJ; e-mail: sandramsacra@uesc.br.
} 


\section{INTRODUÇÃO}

Este artigo tem como objetivo analisar a construção discursiva do corpo feminino na representação literária de donzela-guerreira, e como esse corrobora para a desnaturalização do sexo e para a ruptura dos padrões de gênero. Dessa maneira, observaremos a presença da donzela na tradição ocidental, passando pela literatura brasileira até sua aparição nos romances Luzia-Homem (1903), de Domingos Olímpio; Dona Guidinha do Poço (1965), de Manuel Paiva, Grande Sertão: Veredas (1956), de

Guimarães Rosa e Memorial de Maria Moura, de 1992, de Raquel de Queiroz. Dessa maneira, a partir das representações femininas presentes nas narrativas citadas, analisaremos como funcionam os elementos recorrentes para a composição do corpo da donzela-guerreira.

Buscamos compreender o corpo da donzela como elemento performativo para a construção de uma identidade feminina que dialoga com o masculino, assimilando seu discurso hegemônico para burlá-lo. A compreensão de performatividade aqui adotada é trazida por Butler (2008), na qual as delimitações atribuídas aos corpos são intrínsecas à manutenção constante de normas reguladoras, porém são alternadas constantemente, ou sancionadas pelo sujeito. Nesse contexto, as repetições das ações são tomadas pelo sujeito conscientemente ou não, a fim de formar seu corpo, sexo e gênero.

Pensar a donzela-guerreira nos estudos de gênero é indagar o espaço público e privado ocupado pelas mulheres já que ela se dedica ao âmbito da guerra de predominância masculina, assumindo o discurso do sexo naturalizado sobre o seu corpo. Ela permite trazer para a discussão o jogo de poderes existentes entre os gêneros. Essa figura feminina tem as primeiras representações na sociedade ocidental na Grécia Antiga, nas narrativas de Heródoto, quando relata a saga das amazonas. Na Ilíada, de Homero, com a guerreira Pentessiléia, que enfrenta Ulisses na Guerra de Tróia. Na Eneida, Virgílio, ao celebrar o Império Romano, traz à cena literária Camila, virgem dedicada à Diana, que se sobressai por ser boa guerreira e destra caçadora. Outras guerreiras, que se destacam no mundo greco-romano, são Hipólita, guerreira destemida que luta contra Hércules e Electra, virgem, que, ao buscar vingar-se do assassinato do pai, trama a morte da mãe.

Para Galvão (1998), a primeira donzela-guerreira é Atalanta que pertence à mitologia grega. Ela recém-nascida é abandonada em uma montanha e recebe tal destino por não pertencer ao gênero masculino e frustrar as expectativas do pai. Amamentada por uma ursa, é encontrada e criada por um grupo de caçadores, trajada de homem e se torna hábil em armas e 
caça. Virgem dedicada à deusa Ártemis será a grande vencedora do javali divino. Entretanto, será metamorfoseada em leoa como punição por ter se casado.

Narrativa de origem popular que se propaga na oralidade, a donzela-guerreira penetra a cultura brasileira por meio do colonizador europeu. Ela, primeiramente, ganha destaque na literatura popular por meio dos cantadores, adquirindo características da realidade nacional e, mais tarde, ganha espaço em formas literárias consideradas eruditas, em especial, o romance. A representação dessa figura feminina está atrelada ao discurso patriarcal, no qual predomina a perspectiva androcêntrica ${ }^{3}$.

\title{
2 A DONZELA-GUERREIRA: CORPO E PERFORMANCE NA LITERATURA
}

A temática da donzela-guerreira ocupa romances literários de diferentes épocas. Entretanto pode ser observado que os romancistas brasileiros, ao abordarem o tema, introduzem a personagem em um ambiente, onde predomina o semifeudal ou oligarquias rurais, com a presença de uma hierarquia social de difícil transposição, devido ao autoritarismo dos coronéis (figura máxima do pater familias). Nesse contexto, é predominante a presença da cultura pré-letrada e das relações sociais baseadas no processo de parentesco e apadrinhamento.

\begin{abstract}
É notório que embora pertencentes a épocas e cânones literários diversos, ao elegerem o motivo da donzela-guerreira, nossos ficcionistas são imediatamente levados a utilizar uma mesma orientação espaço/temporal que os leva para lugares distantes do mundo urbano. Em tal cenário deve predominar uma estrutura semifeudal, com condições sociais petrificadas e atreladas às oligarquias rurais e ao mandonismo dos coronéis (nossa versão canhestra do senhor feudal) também expressão máxima do pater-familias. Nesse contexto vigora a cultura pré-letrada e a ordem social estática é baseada em relações de dominação, parentesco e apadrinhamento (OLIVEIRA, 2001, p.16).
\end{abstract}

Nesse âmbito cênico social, a figura masculina predomina sobre a feminina, logo a distinção dos sexos torna-se cada vez mais evidente por meio dos direitos e deveres. $\mathrm{O}$ discurso da donzela não indaga os valores do patriarcado, mas os ameaça, pois os assimila, enquanto gênero feminino que deve estar na ordem discursiva das representações biológicas, de comportamento, de corpo e gênero. Segundo Foucault (1998), o discurso a respeito da

\footnotetext{
${ }^{3} \mathrm{O}$ androcentrismo provém do grego andrós. Refere-se à concepção ou saber supostamente neutro e univera que privilegia o ponto de vista dos homens como eixo articulador ou discurso social e lógico científico, sem considerar ou desvalorizando o ponto de vista das mulheres. (YANNOULAS, VALLEJOS; LEONARDUZZI, 2000, p.426).
} 
sexualidade é organizado para definir os desejos de poder. O discurso sobre a sexualidade não se caracteriza como uma área neutra, mas os interditos que estão no discurso sobre sexualidade supõem a luta pelo desejo e pelo poder. Nesse sentido, a formação do masculino e do feminino obedece à ordem discursiva legitimada pela sociedade, na qual os gêneros se inserem no que é previamente definido como "verdadeiro" e são autorizados a difundir-se por meio do discurso.

[...] em nossos dias, as regiões onde a grade é mais cerrada, onde os buracos negros se multiplicam, são as regiões da sexualidade...: como se o discurso, longe de ser um elemento transparente ou neutro no qual a sexualidade se desarma..., fosse um dos lugares onde estas regiões exercem, de maneira privilegiada, alguns dos seus mais temíveis poderes. Por mais que o discurso seja aparentemente bem pouca coisa, as interdições que o atingem revelam longe, rapidamente sua ligação com o desejo e com o poder (FOUCAULT, 1998, p. 9-10).

A donzela-guerreira encerra aspectos básicos de personalidade que são mantidos e perpetuados, através de sua representação. Desse modo, a personagem apresenta-se na série filial como primogênita ou a caçula, pois o pai não tem filhos homens adultos ou não pode têlos. Outros aspectos da donzela-guerreira são: o fato de se vestir como homem, com seios e ancas cingidos e com a abdicação das fraquezas femininas (faceirice, sustos). Entretanto, ao ser descoberta, costuma sofrer uma morte social ou física.

Ela invade o mundo masculino, cortando o cabelo e vestindo trajes de homens. O corte dos cabelos traz toda uma representação de gênero. A perda dos cabelos representa a aproximação com o modelo do que seja o masculino, na medida em que os cabelos são símbolos de feminilidade, sensualidade, sedução e desejo.

Para o homem, aquilo que cresce em seu corpo é a sua força; donde, para um homem, cortar aquilo que cresce em seu corpo é castração, é perda, é fraqueza. Para uma mulher, cortar aquilo que cresce em seu corpo não é castração, é ganho, é aquisição de força (GALVÃO, 1998, p.175).

O sacrifício dos cabelos vem simbolizar a perda do estereótipo feminino, de docilidade e ternura. O corte marca a entrada da figura feminina no discurso masculino, no qual sua tosquia representa a virilidade. A personagem vai se desatacar também pela aquisição de atribuições sociais, as quais afastam-na do que é estabelecido discursivamente em relação ao seu gênero. Desta sorte, as enunciações tendem a desestabilizar os discursos legitimados sobre a fragilidade física, a maternidade, a virgindade e os espaços de poderes atribuídos às mulheres.

O corpo socialmente representado, por meio do discurso biológico, funciona como elemento de naturalização do sexo, é o que permite à personagem se distanciar dos èspaços đe 
poder conferidos às demais de seu gênero. O corpo, biologicamente distinto de suas iguais em gênero, constitui o elemento propiciador à assunção de uma espécie de performance identitária. O conceito de performatividade move a ênfase do identitário como lugar fixo de representação para a concepção de transformação e movimento. A performatividade é primeiramente formulada dentro dos estudos linguísticos de J. A. Austin (1998). Para ele, a linguagem não se limita à descrição de uma ação, uma situação ou um estado de coisa. Austin aplica à sua teoria proposições que chama de "constatativa" ou "descritivas" e performativas, respectivamente. A primeira está no âmbito da descrição do estado das coisas ou da ação, podendo ser verdadeira ou falsa. Entretanto, a linguagem não se limita a descrever, pois existem enunciações para que o "fato" se efetive ou se realize. É certo que existem preposições descritivas, que funcionam como performativa. Explicando melhor: os atos de fala, através da repetição, constroem o sentido do que é aceito ou não, pela sociedade. Assim, a performatividade está atrelada à produção de uma ação e não é nem verdadeira, nem falsa, entretanto, mantém-se somente em atenção às circunstâncias de legitimação conferida ao sujeito.

Laqueur (1990) argumenta que as transformações políticas, econômicas e culturais do século XVIII criam um contexto alicerçado nas diferenças entre os sexos, de forma mais radical. Ele argumenta que, até o século XVIII, o discurso dominante "construiu os corpos masculino e feminino como versões hierárquica e verticalmente ordenadas de um único sexo" (LAQUEUR, 1990, p.10). Nesse período, para o autor, o corpo feminino era compreendido como uma versão inferior e invertida do masculino, e, de certa maneira, havia ênfase sobre a importância da função feminina no prazer sexual, especialmente no processo da reprodução. O orgasmo feminino e o prazer serviriam para assegurar uma fecundação bem-sucedida. A substituição desse modelo no século XIX, por outro baseado no ciclo reprodutivo da mulher, afirmaria a ausência de sensação sexual da mulher e a oposição das sexualidades masculina e feminina como corpos singulares.

As questões pertinentes aos corpos e ao comportamento sexual têm ocupado o centro das preocupações ocidentais. Até o século XIX, elas recebiam atenção principalmente da religião e da filosofia moral. No final do século XIX, a temática recebe sua própria disciplina, a sexologia, a qual tem por base a psicologia, a biologia e a antropologia, a história e a sociologia. O sexo é tomado a princípio, como um "instinto natural", a fim de atender às necessidades fundamentais do corpo, em uma linha evolucionista pós-darwiniana do fina@do século XIX, que tendeu a explicar os fenômenos humanos através de forças identificáveis, internas, biológicas. Embora a perspectiva biológica ainda esteja presente hoje, existe uma 
vasta literatura que aponta a sexualidade como "uma construção social", um invento histórico, o qual adquire significação natural, nas superfícies dos corpos. A representação de sentido, que lhe atribuímos, passa a ser modelado em situações sociais concretas o que ocasiona investiduras para nossa compreensão do corpo, do sexo e da sexualidade, implicações essas que precisaremos explorar.

A sociedade tende a "celebrar" o sexo com uma visão simplória, observado tão somente como um aspecto natural de atuação sobre os corpos, a pressionar, de forma urgente e incessante, os sujeitos conscientes. Foucault (1993) contesta a visão naturalista e essencialista conferida ao sexo. Para ele, a sexualidade passa a ser entendida como um "aparelho histórico", desenvolvido a partir de uma rede complexa que organiza e modela os corpos e os comportamentos dos sujeitos. A sexualidade atua como um dos modos pelos quais o poder se firma sobre a sociedade moderna "Não se deve concebê-la como uma espécie de dado da natureza que o poder tenta pôr em xeque, ou como um domínio obscuro que o saber tentaria, pouco a pouco, desvelar. A sexualidade é o nome que se pode dar a um dispositivo histórico" (FOUCAULT, 1993, p.100).

Nesse contexto, a história da sexualidade será elaborada a partir de discursos que a constrói, como uma elaboração de conhecimento, que modela as formas de pensar e de conhecer o corpo. Na sociedade ocidental, o discurso sobre a sexualidade não é repelido, mas se torna constante e historicamente alternado por meio do incitamento ao discurso sobre o sexo. O discurso sobre a sexualidade se torna eficaz por meio da produção, que estabelece uma série de concepções sobre os limites de atuação do corpo "O dispositivo da sexualidade tem, como razão de ser, não o reproduzir, mas o proliferar, inovar, anexar, inventar, penetrar nos corpos de maneira cada vez mais detalhada e controlar as populações de modo cada vez mais global" (FOUCAULT, 1993, p.101). A sexualidade é dos mecanismos de regulação social, tendo em vista que o sexo é um meio de regulação tanto dos corpos individuais, quanto do comportamento dos sujeitos.

Foucault aponta que, desde o século XVIII, quatro unidades atuam como mecanismos de conhecimento e poder centrados no sexo. Elas abrangem a sexualidade das mulheres; a sexualidade das crianças; o controle do comportamento pro criativo e a demarcação de perversões sexuais como problemas de patologia individual. Consequentemente, no século XIX, essas estratégias produzem a mulher histérica; a criança, que se masturba; o casal, que utiliza formas artificiais de controle de natalidade e o "pervertido", especialmentes homossexual. Todos esses indivíduos tornam-se submetidos ao controle social, originado no interior de discursos reguladores. Logo, a sociedade, ao criar mecanismos de regulação, a fím 
de manter a moral, a prosperidade econômica, a segurança nacional, a higiene e da saúde, acaba por enfatizar o disciplinamento dos corpos e a prescrição do comportamento sexual.

Historiadores irão apontar o período vitoriano como fundamental para o entendimento sobre a regulação da sexualidade e do corpo, tendo em vista o caráter repressivo da época. Dessa maneira, a sexualidade feminina era duramente regulada para assegurar a "pureza", entretanto, simultaneamente, a prostituição era abundante. $\mathrm{O}$ controle das doenças venéreas, que ameaçavam a saúde pública do período, era buscado pela repressão à sexualidade feminina, ao invés da masculina. O século XIX se torna fundamental para ratificar a sexualidade feminina "Os termos dessa definição têm influenciado fortemente nossos próprios conceitos, bem como nossos pressupostos sobre a importância das diferenças corporais" (WEEKS, 2000, p 40).

É perceptível que corpo e gênero obedecem a um discurso naturalizado, enquanto construções discursivas arbitrárias; na medida em que é somente no interior dos sistemas de representação das culturas que os corpos adquirem significado. O corpo das donzelas, aqui estudas, encerram constructos para uma tomada de poder. E, ao se travestirem, assumem uma espécie de rito em performance, em atenção ao lugar, previamente acordado pela representação social, constante do discurso patriarcal. Nesse contexto, observamos que o discurso da donzela está associado às heranças paternas.

\section{AS REPRESENTAÇÕES DE DONZELA-GUERREIRA NO LITERÁRIO}

Na Literatura Brasileira a donzela-guerreira marca presença em romances como LuziaHomem (1903), de Domingos Olímpio; Dona Guidinha do Poço (1965), de Manuel Paiva, Grande Sertão: Veredas (1956), de Guimarães Rosa e Memorial de Maria Moura, de 1992, de Raquel de Queiroz. Tais obras norteiam a figura da donzela a fim de cumprir sua heroica e emblemática história. Dessa maneira, as elegemos a fim de compreender como a representação do corpo feminino corrobora para a ruptura do discurso a respeito dos deveres e poderes atribuídos ao gênero.

O romance Luzia-Homem, de Domingos Olímpio, por exemplo, coloca sob suspeita a racionalidade científica, que caracteriza o discurso estético naturalista do final do século XIX e o transfere para o âmbito popular de ver o mundo. Esse é conseguido por meio das enunciações de Luzia-Homem, Raulino e Rosa Veado. Além disso, desconstrói não somente o suporte teórico-científico, mas, ao mesmo tempo, substitui as personagens histéricas intrínsecas do naturalismo pela figura da donzela-guerreira. Dessa maneira, ocorrè também a 
mudança do ambiente urbano, cenário dos romances naturalistas, para a descrição de grandes áreas de terra e paisagens abertas.

Luzia-Homem legitima seu discurso na força física que é comparada à de um homem "Não lhe acho graça [...] Depois [...] com semelhante força [...] nem parece mulher [...]." (OLÍMPIO, 1973 p.32). Em Luzia-Homem, é observado que a ação da personagem está atrelada ao discurso paterno, com isso são buscados os ensinamentos e os modos de representações masculinas.

Eu lhe digo, seu doutor. Desde menina fui acostumada a andar vestida de homem para poder ajudar meu pai no serviço. Pastorava o gado; cavava bebedores e cacimba; vaquejava a cavalo com o defunto; fazia todo o serviço da fazenda, até o de foice e machado na derrubada dos roçados. Só deixei de usar camisa e ceroula e andar encoirada, quando já era moça demais, ali por obra dos dezoito anos. Muita gente me tomava por homem de verdade. Depois meu pai, coitadinho, que era forte como um touro, e matava um bode taludo com um murro no cabeloiro, morreu de moléstias, que apanhou na influência da ambição de melhorar de sorte, na cavação de ouro no riacho de Juré (OLIMPIO, 1973 p.32).

Na narrativa Luzia-Homem, ocorre à transposição do discurso positivo masculino para a figura feminina de Luzia. Para tanto, o discurso narrativo é elaborado por meio do macho viril e forte, o qual possui uma força fora do comum. Entretanto, nesta obra, o atributo da força física é transposto para uma mulher "Em plena florescência de mocidade e saúde, a extraordinária mulher [...] encobria os músculos de aço sob as formas esbeltas e graciosas das morenas do sertão" (OLÍMPIO, 1973 p.16). Nesse sentido, o narrador desconstrói, em LuziaHomem, a definição de feminilidade postulada no final do século passado, a qual via a mulher como sexo frágil e lhe atribuía apenas tarefas domésticas. Dessa maneira, a força física de Luzia-Homem se complementa com sua beleza de fêmea e permite que o discurso de donzelaguerreira seja legitimado. Para Beauvoir (1991), "No tempo em que se tratava de brandir [...], de enfrentar animais selvagens, a fraqueza física da mulher constituía uma inferioridade flagrante" (BEAUVOIR, 1991, p.73). Em Luzia-Homem, a fraqueza feminina, por outro lado, é retirada, o que a deixa em grau de igualdade com os machos; fazendo com que a figura da donzela-guerreira desautorize o discurso patriarcal presente no discurso dominante.

O discurso narrativo, situado no período de 1878, tem em suas condições de produção discursiva uma sociedade patriarcal. Nesse contexto, o discurso utiliza um dos principais valores da figura masculina - a virilidade - demonstrada mediante a recorrência da força física, pois "Provar sua virilidade", [...] "exige que o homem, com frequência, manifeste brutalidade, [...] e tenha reações rápidas e agressivas" (BADINTER, 1993, p.143), O discureso da personagem permite que identifiquemos tal perspectiva, quando a mesma faz uso da força física para confrontar o soldado Crapiúna. A figura do soldado corrobora para que a 
personagem Luzia seja o outro do gênero masculino, pois sob os músculos poderosos, o discurso de Luzia é o de fêmea frágil: "Sob os músculos poderosos de Luzia-Homem estava uma mulher tímida e frágil, afogada no sofrimento que não transbordava em pranto, e só irradiava em chispas fulvas, nos grandes olhos de luminosa treva" (OLÍMPIO, 1973, p. 23).

Sem dúvida, o discurso a respeito de machos e fêmeas influencia a maneira pela qual ambos devem se comportar em sociedade. Assim, os corpos submetidos a discursos produzem nos sujeitos consciência dos valores pertinentes a seu gênero, aos quais devem se adequar. Luzia, enquanto mulher com força masculina era vista com estranheza pelas demais do seu gênero "Mulher que tinha buço de rapaz, pernas e braços forrados de pelúcia crespa e entornos de força, com ares varonis, [...] deverá ser um desses erros da natureza [...]” (OLÍMPIO, 1973, p.24).

Noutra perspectiva, a donzela-guerreira tem seu discurso de gênero feminino mantido, pois assume valores do gênero. Desse modo, a mesma sustenta o discurso que o gênero masculino é livre de sanções sociais relacionadas ao sexo. O discurso produz uma sexualidade ainda vista como um tabu, na qual a virgindade é um dos principais atributos femininos. Essa perspectiva deve-se ao contexto de produção da narrativa escrita no século XIX. Desse modo, percebe-se que o corpo da mulher influencia a sua situação em sociedade, já que esse é visto como um diferenciador entre machos e fêmeas, que, para tanto, devem obedecer a padrões sociais. Nesse contexto, o discurso narrativo faz uso do discurso biológico para produzir uma donzela-guerreira forte fisicamente e frágil psicologicamente. Assim, por meio da fragilidade psicológica, o discurso narrativo constrói a perspectiva de fêmea indefesa.

Outro romance que se destaca na literatura sobre a donzela-guerreira é Dona Guidinha do Poço, de Oliveira Paiva (1965). O romance traz à cena literária a questão do adultério, assim Guida (Margarida), casada com Major Joaquim Damião (Major Quinquim) tem um amante por nome Secundino, que é sobrinho do marido. No romance em questão, existe a ausência de travestimento da personagem feminina com roupas masculinas. Em determinadas enunciações da narrativa, as ações de Guida são comparadas como pertencentes ao gênero masculino.

Nadava de braça como os homens, e não como as mulheres, que trabalham com as mãos por debaixo d'água, pelo instinto do pejo, e vão assim batendo com os pés à tona. [...] Amara à Margarida em demasia, creio, e o vigor nervudo e musculento da herdeira do marinheiro Reginaldo Venceslau era como um moirão (PAIVA, 1965, p.16-19). 
Observamos que a narrativa se dedica ao relato de uma heroína que se desvia dos padrões tradicionais de mulher do século XIX. Com isso, desenvolve a figura de Guida, uma sertaneja bravia, que busca atender apenas às suas vontades: “A Guida, mãos rotas, que fazia derramar ancoretas de vinho nas suas festas, senhora de suas ventas, coração bravio, essa era extremada no proteger ou no perseguir" (PAIVA, 1965, p.31). Ela possui certo traço voluntarioso, quase masculino, devidamente estimulado pela educação recebida do pai, desgostoso de não ter tido um filho homem.

Guida assume seus desejos e sua sexualidade "Margarida era muitíssimo do seu sexo, mas das que são pouco femininas, pouco mulheres, pouco damas, e muito fêmeas" (PAIVA, 1965, p.17). A incorporação do discurso masculino à personagem Guida permite a desconstrução da ordem legítima dos papéis sexuais pré-estabelecidos, como evidencia Süssekind (1984): “O simples fato de tomarem a si encargos masculinos joga por terra à divisão sexual de papéis na sociedade do fim do século" (SÜSSEKIND, 1984 p.148). Guida é inserida numa esfera de atuação masculina, no âmbito do trabalho, do poder, da propriedade e se afasta das atribuições bem definidas de esposa e mãe.

A personagem permite evidenciarmos a condição de mulher livre e rica no sertão do século XIX já que a protagonista é filha de um fazendeiro e herdou o patrimônio de seu pai "Margarida, isto é, a Guidinha [...]. Seu pai, o segundo Venceslau, capitão-mor da vila, possuía larga fortuna em gados, terras, ouros, escravos...” (PAIVA, 1965, p. 13). Através da personagem, observamos um dos tipos físicos de mulheres pertencentes às classes abastadas "Não parecia contar já os seus trinta e cinco anos de idade. Os cabelos, tinha os de um castanho encrespado, e a pele lisa, [...]" (PAIVA, 1965, p.22).

Dessa maneira, Del Priore (2001) aponta para dois tipos físicos predominantes entre as mulheres livres e fazendeiras do sertão. O primeiro seria composto por mulheres com o cabelo crespo, os lábios grossos, "a tez levemente amorenada", essas representariam tipos miscigenados. O outro e mais comum incorporaria as mulheres de origem europeia. Assim, possuíam "o nariz regular, a fonte elevada" pescoço e cabelos finos "corridos, mas lustrosos".

As mulheres da classe abastada no sertão eram educadas para desempenhar o papel de mãe e para o trabalho doméstico, o qual incluía a orientação dos filhos, a costura, o bordado e a cozinha. Nesse contexto, no sertão, a preocupação com casamento era uma questão familiar. Com isso, o casamento da elite era um acordo entre famílias. Assim, após "as primeiras regras" (menstruação), se iniciava a procura por um pretendente. Consequentemente@ relações conjugais eram marcadas por fatores econômicos e políticos, sendo åafinidade da ordem dos sentimentos e sexual algo de menor importância para a realização matrimonial. 
Em Dona Guidinha do Poço, não há a preocupação da personagem em se casar cedo, como pode ser evidenciado no seguinte fragmento: "Margarida, isto é, a Guidinha, apesar de sua princesa, não casou tão cedo como era de supor. Parece que primeiro quis desfrutar a vidoca" (PAIVA, 1965 p.13). Ademais, a narrativa evidencia uma postura vedada à perspectiva do gênero feminino. Senhora de seu destino, Guida, ao se sentir insatisfeita no matrimônio, busca nos braços de um amante a realização individual: "Margarida às vezes sentia não poder casar bem, frisar, bem, dar certo com o esposo que recebeu no pé do altar. $\mathrm{E}$ nesses estados de alma se atirava ao homem, a ver se enfim encontrava essa felicidade tão falada, que não conhecera jamais" (PAIVA, 1965, p.99).

Os limites impostos à atuação dos corpos, no âmbito da sexualidade, são verificados, principalmente, quando a prática é o adultério feminino. O código matrimonial, como norma de conduta, introduz inúmeros ritos e interditos determinando as fronteiras entre o lícito e o ilícito, o puro e o impuro. A imposição de limitações à sexualidade no casamento, impostas pela moral cristã burguesa, induz os sujeitos a uma sexualidade controlada. Para a mulher, cabe o discurso de mãe-esposa, que atua contra a sensualidade, o desejo e a sexualidade. É atribuído ao gênero a virtude cerceadora ou o pecado punível. Em relação ao homem, apesar das imposições eclesiásticas e sociais condenarem o sexo fora do casamento, a moral é leniente; na medida em que o adultério masculino é aceito de forma corrente como prova de virilidade.

Condenável apenas quando praticado pelo gênero feminino, o adultério não foi exclusividade do sertão nordestino. Entretanto, no sertão do século XIX, fatores específicos corroboravam para a prática como o desequilíbrio demográfico das regiões interioranas. Dessa maneira, o mercado matrimonial seria desvantajoso para um grande número de mulheres, cujo marido saía do sertão para morar em cidades litorâneas e formava novas famílias, como deixa claro Del Priore: "Homens de prestígio e de boa situação social sempre tiveram possibilidade de constituir duas ou três famílias", porque "era a vertente culta que intimidava os humildes" (DEL PRIORE, 2001, p.269). Nesse contexto, homens mais velhos, detentores de poder social e financeiro, constituíam mais de uma família. As cunhãs ou amásias possuíam menor poder aquisitivo e com o relacionamento passavam a ter prestígio social, advindo do cargo exercido pelo "marido" e certo respeito principalmente se da união existissem filhos. No mais, a sociedade exigia da "cunhã" um comportamento adequado e comedido. Essa deveria "ser conhecedora de seu lugar", o qual não se confundia con prestígio social da esposa

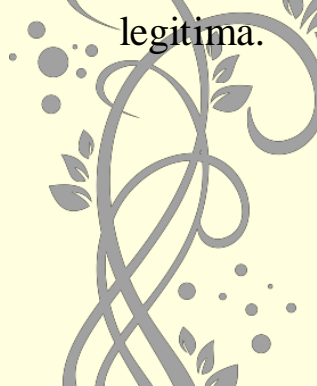


O sertão nordestino do século XIX seria marcado por uma sociedade patriarcal e altamente estratificada entre homens e mulheres. Dessa maneira, prevaleciam as rígidas hierarquias, as quais se estruturavam a partir do poder aquisitivo, o gênero e a cor da pele. Nesse contexto, se legitimava uma ordem social, na qual o homem estaria acima de tudo, podendo ocupar a condição de fazendeiro, político ou doutor e mesmo mantenedor de várias mulheres e filhos.

Em Grande: Sertão Veredas (1994), de Guimarães Rosa, Diadorim é outra personagem que integra a "galeria" das donzelas-guerreiras. A narrativa guarda em sua composição uma relação com a produção oral. Na estrutura oral, ocorre o lamento do pai por não ter um filho que o represente na guerra o que induz a filha a representá-lo como guerreiro, travestida de homem para não ser reconhecida. No romance em questão, não ocorre à apresentação desse espaço organizado anterior à condição de guerreiro. Tida, desde o início, como jagunço, a personagem não evidencia os laços familiares e da infância. Assim, apenas a morte da mãe e existência de um tio integram o quadro de memórias.

A elaboração de Diadorim tem como operador principal a figura paterna “"Meu pai disse que não se deve de ter [...]' (...) - Meu pai é o homem mais valente deste mundo" (ROSA, p.146). A composição dessa donzela se mostra especial, pois conta com a presença do pai no campo de batalha. No decorrer do romance, a relação entre ambos é ocultada pelo distanciamento e pelo segredo mantido entre pai e filha. Dessa maneira, o jagunço Reinaldo não é reconhecido por todos do bando como filho de Joca Ramiro.

As roupas do guerreiro ajudam em sua composição. Vestida com calças de vaqueiro, que jamais retirava Diadorim, com sua aparência física, afirma sua posição de macho dentro do bando. É certo que o fato de se travestir de masculino, a faz assumir o pressuposto de que a vestimenta serve para materializar o discurso de gênero sobre o corpo. Nesse contexto, problematiza a relação entre o masculino e o feminino no tocante à inserção de valores histórico-culturais, que delimitam o que deve ou não ser usado por determinado gênero; em reforço da ideia de que os trajes impõem significado sobre o corpo representado.

Os romances pontuados acima servem de matriz para o romance Memorial de Maria Moura. Maria Moura tem o discurso marcado por ensinamentos paternos. Sentimentos de admiração e respeito marcam a relação entre pai e filha. Com isso, na narrativa, a performance feminina tem como elemento motivador a memória das atitudes paternas. "É a força paterna a maior responsável pela elaboração das façanhas de Maria Moura, em formae memorial. Essa figura intrínseca marca presença nos escritos de fatos memoráveis de Maria, tornando-a Moura" (VILALVA, 2004, p.35). Inúmeras vezes, referendada nooromance, 
personagem Pai é um dos legitimadores das ações da Moura. É por meio do Pai que ela toma conhecimento das histórias de família passadas entre os parentes do Limoeiro e os da Maria Preta. Ele também é a "voz" que conduz Maria Moura para a Serra dos Padres. O discurso paterno adquire valor inquestionável, se materializando na própria verdade sobre as coisas:

\begin{abstract}
Eu tinha planejado a defesa e o incêndio, mas agora a minha idéia era vaga. Na primeira hora procurava só respirar bem fundo e tomar o cheiro daquela liberdade. Não me doía tanto quanto esperei o fogo na casa do Limoeiro; afinal agora tinha chegado a vez de cumprir o meu grande sonho. As terras da Serra dos Padres, tudo fresco, olho d'água correndo entre as pedras. Pai falava tanto, era o mesmo que eu já tivesse visto. Tinha a questão com os posseiros; mas pelo que Pai dizia, o pior deles já tinha morrido; (...) (QUEIROZ, 1992, p.79).
\end{abstract}

A conquista da Serra dos Padres é ambicionada tanto pelo Avô quanto pelo Pai de Maria Moura, passando a integrar posteriormente o desejo da heroína. A incessante busca das terras funciona como elemento que influenciará a composição da identidade da personagem, pois a procura a faz abdicar da condição de donzela presa a preceitos de classe e gênero e a molda como guerreira. Assim, as histórias contadas pelas figuras masculinas desde a infância conduzem-na em busca do poder, configurado na aquisição de terras.

\begin{abstract}
Já as outras terras, que a gente tinha certeza que eram nossas, ficavam nem eu sabia mais a quantas léguas, sertão adentro. E reaver essa posse era o sonho do meu avô por parte de pai, e depois de morto o Avô, passou a ser o sonho de Pai, filho dele (p.21).

Deitada no mato, olhando as estrelas no céu escuro, eu ia me lembrando das conversas do Avô, os casos que ele me contava tantas vezes, tantas. Começou a contar quando eu era pequena e me deitava com ele, em noite de lua, na rede do alpendre. Depois eu já mocinha, ouvia os mesmos casos, repetidos já agora por Pai, às visitas, aos parentes. E muito mais explicados do que no tempo em que ainda eu não podia entender (QUEIROZ, 1992, p.87).
\end{abstract}

A posse da terra exigirá de Maria Moura a perda da imagem de Sinhazinha. As indumentárias paternas participam também da nova imagem de Moura, como pressuposto inicial para a liderança sobre os homens. Entretanto, a formação de bando não se configura como uma constante na temática da donzela-guerreira; ainda que as escolhas a integrar uma sociedade marginal e, muitas vezes, criminosa, sejam características próprias das donzelas brasileiras, narradas neste tipo de narrativa.

Segundo Woodward (2003) "O corpo é um dos locais envolvidos no estabelecimento das fronteiras que definem quem nós somos, servindo de fundamento para a identidade, por exemplo, para a identidade sexual" (WOODWARD, 2003, p.15). Senhora de sen des(îO, Maria Moura é líder de seu bando e de seu corpo. A sexualidade da Moura é aflorada e nela seus desejos prevalecem, na medida em que as relações amorosas com as personagens 
masculinas são baseadas no desejo de poder "tinha que ter ouro para ter poder" (p. 177). Porém, para adquirir poder, dentro dos espaços de representações de gênero, ela se veste de jagunço e toma para si o discurso masculino. A composição de sua imagem corporal está associada à de uma mulher de natureza bravia; para tanto, alguns comparações com animais marcam a personagem: “uma onça” (QUEIROZ, 1992, p.50), "jaguatirica” (QUEIROZ, 1992, p. 51) ou "natureza de fera" (QUEIROZ, 1992, p.89).

No decorrer do romance, é perceptível que, em algumas passagens, a condição de mulher chefe de bando é indagada por parte da personagem, levando-nos à compreensão de um deslocamento dentro do âmbito de representação. Assim, em determinadas passagens, Maria Moura explicita a necessidade de uma presença masculina, que complementaria a feminina: "toda mulher quer ter um homem seu, como sua mãe lhe ensinava" (QUEIROZ, 1992, p.201). Certamente, as afirmativas de Maria Moura permitem que os paradigmas relacionados à ordem patriarcal sejam evidenciados como a submissão feminina "queria ter um homem me exigindo, me seguindo com um olho cobiçoso, com ciúme de mim, como se eu fosse coisa dele" (QUEIROZ, 1992, p.202).

A postura assumida pela Moura de chefe de bando não invalida sua identidade feminina. Com isso, lança questões sobre o casamento, rememora seus casos amorosos. Entretanto, seu desejo de poder e de comando a faz abdicar das funções sociais conferidas ao seu gênero "[...] eu tinha horror a casamento. Um homem mandando em mim imagine; logo eu, acostumada, imagine, desde anos a mandar em qualquer homem" (QUEIROZ, 1992, p.324). A identidade feminina é construída, ao longo da narrativa, com discursos que representam socialmente o gênero masculino e feminino. Desse modo, a personagem, antes de se tornar a líder dos jagunços da Serra dos Padres, era Sinhazinha do Limoeiro, que, motivada por fatores de disputa de terras, se modifica para adquirir poder.

As relações amorosas de Maria Moura também são marcadas pela condição de mando. Dessa maneira, quando manteve contato amoroso com seu primo Duarte, o qual também integrava o bando, ela deixa clara a condição de chefe "[...] comigo, quando se tratasse de homem, tinha que ser sempre eu quem dava o sinal" (QUEIROZ, 1992, p.324). Em outra perspectiva, ocorre com a personagem Cirino; pois, embora haja resistência, Maria Moura chega a "sofrer de paixão por um homem" (QUEIROZ, 1992, p.337). Mas, quando este ameaça sua condição de hegemonia, não hesita em mandar matá-lo "foi um amor desesperado que doía e machucava; amor de dois inimigos, se mordendo e se ferindo, como se quisessem@e aquilo acabasse em morte" (QUEIROZ, 1992, 
O corpo da mulher é atravessado por leis de poder, que determinam modos de vesti-lo e comportamentos a serem mantidos, "corpo desejado, o corpo das mulheres é também, no curso da história, um corpo dominado e subjugado, muitas vezes roubado, em sua própria sexualidade" (PERROT, 2004, p.76). Trata-se de um corpo moldado para ser depositário de características, que o limitam, enquanto espaço de subjetividade, sem que sejam permitidas, com facilidade, outras identificações, além do discurso pré-estabelecido para o feminino, visto o corpo ser o elemento que materializa o sexo, delimitando o gênero.

Entretanto, os aparelhos de regulação não são modelos totalmente fechados, o que permite modificações identitárias nas categorias homem/masculino e mulher/feminino. No mais, abre prerrogativa para que outras identificações de sexo e gênero possam ser criadas por este mesmo sistema. Maria Moura, assim, rompe com a repetição performática, no que tange à relação gênero-corpo e atributos sociais; sendo o seu corpo elemento de performance, que enseja um novo paradigma de gênero.

\section{CONSIDERAÇÕES FINAIS}

O corpo da donzela funciona como elemento performático de busca pelo poder. Dessa forma, as enunciações das personagens as distanciam dos padrões de gênero das sociedades representadas, pois negligenciam os papéis sociais de mãe, esposa e da ausência de desejo sexual feminino. Elas se dedicam ao âmbito da guerra, espaço de dominação masculina e conseguem destaque nos espaços públicos.

Butler defende a performatividade como elemento necessário à questão do identitário. Os papéis assumidos por homens e mulheres passam a ser compreendidos pelo "deslocamento" do discurso. Nesse contexto, os aspectos cognitivos e ideológicos dos sujeitos são construídos pelo discurso e, simultaneamente, esse também é o responsável pela construção dos corpos de machos e fêmeas. Nascidos os corpos, os discursos interpelam os sujeitos, formatando-os na díade sexo/gênero. Logo, as identidades de homens e mulheres são arrebatadas pela performance "negociada" pelas relações de poder.

É perceptível que os sistemas de representação sobre a sexualidade, assim como os demais presentes na cultura estão atrelados à luta e à manutenção do poder. Desse modo, homem e mulher, antes de tudo, são produtos de uma construção discursiva, nâ qué estabelecida uma hierarquia, um papel social. A figura da donzela-guerreira desconstrói os parâmetros sociais de gêneros já que permite que o feminino transite no âmbito masculino 
Com isso, ganha destaque na atualidade, construindo a imagem de uma "mulher perfeita" que não possui as limitações do gênero. No mais, é compreensivo que masculinidade e feminilidade são discursos correlacionados, no qual o discurso identitário que um assume ratifica o que o outro não deve ser. A donzela trabalha com a ruptura da visão tradicional acerca do modelo feminino, pautando sua argumentação em pressupostos pós-modernos, nos quais as concepções não devem se apresentar dotadas de discursos homogêneos.

Nas representações de donzela-guerreira, o discurso é legitimado por meio da transposição das enunciações conferidas ao masculino como positivo para a figura feminina. Tal perspectiva é conseguida por meio de um discurso feminino baseado na disputa pelo poder e dos valores de virilidades. O discurso da donzela apresenta uma mulher, que, para legitimar sua ação dentro de uma sociedade patriarcal, usa o discurso masculino. Dessa maneira, desautorizam-se as figuras masculinas, que são cerceadas em seus papeis previamente autorizados para o seu gênero, em apoio à determinada cena sócio histórica.

\section{REFERÊNCIAS}

AUSTIN, John Langshaw. Quando dizer e fazer: palavras e ação. Tradução de Danilo Marcondes de Souza Filho. Porto Alegre: Arts Médicas, 1990.

BADINTER, Elisabeth. XY: sobre a identidade masculina. Tradução de Maria Ignes Duque Estrada. Rio de Janeiro: Nova Fronteira, 1993.

BARBOSA, Lúcia Dias Leite. Protagonistas de Rachel de Queiroz: caminhos e descaminhos. São Paulo: Pontes, 1999.

BEAUVOIR, Simone de. O segundo sexo. Tradução de Sérgio Millet. Rio de Janeiro: Nova Fronteira, 1991.

BEAUVOIR, Simone de. O segundo sexo. Tradução de Sérgio Millet. Rio de Janeiro: Nova Fronteira, 2009.

BOURDIEU, Pierre. A dominação masculina. Tradução de Maria Helena Kühner. Rio de Janeiro: Bertrand Brasil, 2002.

BOURDIEU, Pierre. O poder simbólico. Tradução de Fernando Tomaz. São Paulo:Difê, 1989. 
BUTLER, J. Corpos que pesam: sobre os limites discursivos do "sexo", in: LOPES LOURO, G. (org.). O corpo educado. Pedagogias da sexualidade. Belo Horizonte: Autêntica, 2000.

BUTLER, Judith P. Problemas de Gênero: feminismo e subversão da Identidade. Tradução de Renato Aguiar, Rio de Janeiro: 2008.

CHIAPPINI, Lígia. Rachel de Queiroz: invenção do Nordeste e muito mais. In: .Literatura e cultura no Brasil: identidades e fronteiras. São Paulo: Perspectiva, 2002. p. $157-176$.

Del PRIORE, Mary (Org.) História das mulheres no Brasil. São Paulo: Contexto, 1997.

Del PRIORE, Mary (Org.) Histórias do Cotidiano. São Paulo: Contexto, 2001.

FOUCAULT, Michel. A ordem do discurso: aula inaugural no College de France, pronunciada em 2 de dezembro de 1970. 4. ed. Tradução de Laura Fraga de Almeida Sampaio. São Paulo: Loyola, 1998.

FOUCAULT, Michel. História da sexualidade I: a vontade de saber. Tradução de Thereza da C. Albuquerque. Rio de Janeiro: Graal, 1988.

FOUCAULT, Michel. História da sexualidade III: $o$ cuidado de si. Tradução de Maria Thereza da C. Albuquerque. Rio de Janeiro: Graal, 1985.

GALVÂO, W.N. A Donzela-Guerreira um caso de Gênero. São Paulo: SENAC, 1998.

LAQUEUR, T. Making sex: body and gender from the Greeks to Freud. Londres:HarvardUniversity Press, 1990.

OLIMPIO, Domingos. Luzia Homem. São Paulo: Ed Três, 1973.

OLIVEIRA, Pedro Paulo de. A construção social da masculinidade. Belo Horizonte; Rio de Janeiro: Ed. UFMG/ IUPERJ, 2004.

OLIVEIRA, Valdelici Batista de Melo. Figurações de Guerreira Donzela nos romances Luzia-Homem e Dona Guidinha do Poço. UNICAMP, 2001.

OLIVEIRA, Adriana Vidal de. A Expressão Constituinte do Feminismo: por uma retomada do processo liberatório da mulher. 2007. 179 f. Dissertação (mestrado)Pontifícia Universidade Católica do Rio de Janeiro, Rio de Janeiro, 2007. 
PAIVA, Manuel de Oliveira. Dona Guidinha do Poço. Rio de Janeiro. Ediouro, 1965. PERROT, Michelle. As mulheres ou os silêncios da história. Trad.: Vivian e Ribeiro. São Paulo: EDUSC, 1998. 520 p.

, Michelle. Os excluídos da história: operários, mulheres e prisioneiros. $2^{\mathrm{a}} \mathrm{ed}$, Rio de Janeiro: Paz e Terra, 1988. 332p.

, Michelle. Minha história das Mulheres. Trad.: Angela M. s. Côrrea. São Paulo: Contexto, 2007. 159.p.2000.

QUEIROZ, Rachel de. Memorial de Maria Moura. 5 ed. São Paulo: Siciliano, 1992.

ROSA, João Guimarães. Grande Sertão: Veredas. Ed. Rio de Janeiro: Nova Aguilar, 1994.

SACRAMENTO, Sandra M. P do. Nação, identidade e gênero na literatura brasileira. Rio de Janeiro: Caetés, 2004.

SACRAMENTO, Sandra. Mulher e Literatura: do cânone ao não-cânone. Revista da ANPOLL, v. 1, n.33, 2012, p. 251- 266.

SCOTT, Joan Walach. A Cidadã paradoxal: As feministas francesas e os direitos do homem. Tradução de Élvio Antônio Funck. Florianópolis: Mulheres, 2002.

SÜSSEKIND, Flora. Tal Brasil, qual romance? Uma ideologia estética e sua história : o naturalismo. Rio de Janeiro: Achiamé, 1984.

TAMARU, Ângela Harumi. A construção literária da mulher nordestina em Rachel Queiroz. 2004. 188 f. Tese (Doutorado) - Universidade Estadual de Campinas, Campinas, 2004.

TEIXEIRA, Sylvia Maria Campos. Aspectos Estilísticos e Pragmáticos da Língua Portuguesa. Ilhéus: Editus, 2013.

VILALVA, Walnice Aparecida Matos. Marias: estudo sobre a donzela-guerreira no romance brasileiro. 2007. 193 f. Tese (Doutorado) - Universidade de Campinas, Campinas, 2004.

WEEKS, Jeffrey. O Corpo e a Sexualidade. In: LOPES LOURO, G. (org.). O co(p) educado. Pedagogias da sexualidade. Belo Horizonte: Autêntica, 2000. 
YANNOULAS, Silvia Cristina; VALLEJOS, Adriana Lucila; LENARDUZZI, Zulma Viviana. Feminismo e academia, Trad. Syomara Deslandes Tindera, Brasília, v. 81, n. 199, p. 425-451, 2000.

Recebido em 07 de julho de 2014 Aceito para publicação em 17 de agosto de 2014 